of the Association to deal with veterinary science, a suggestion which was made by the Netherlands delegation and accepted by the assembly. It was also decided to consider the possibility of holding at the 1953 congress a special session on high-speed cinematography.

The officers of the Association elected unanimously for 1952-53 were as follows: President, John Maddison (Great Britain) ; Vice-Presidents, Jan Korngold (Poland) and Prof. Mario Ponzo (Italy) ; Honorary Treasurer, J. W. Varossieau (Holland) ; and Honorary Secretary, Jean Painlevé (France). In addition, Luc Haesearts (Belgium) was re-elected as curator of the International Film Reference Library and Prof. R. V. Talice (Uruguay) was appointed as delegate for Latin America; Dr. G. Wolf (West Germany) was elected chairman of the Research Section, and Prof. Dekking (Holland) chairman of the Medical Section.

Great Britain was represented at the congress by a strong delegation led by Dr. Malcolm Donaldson, which also included Prof. H. Dryerre, representing the Scottish Scientific Film Association. At the end of the final session of the Assembly, it was unanimously agreed to accept the invitation of the British delegation to hold the seventh congress in London during September 1953.

J. STEWART COOK

\section{INSULATION OF ELECTRICAL EQUIPMENT}

A

VACATION 'school' on the insulation of electrical equipment was held in the Electrical Engineering Department of the Imperial College of Science and Technology, London, during September 15-19. It was attended by some eighty engineers drawn from industry, the British Electricity Authority, research associations, technical colleges and the universities. The purpose of the course was to consider the factors which are limiting insulation design in the main classes of electrical equipment, and the general principles which should govern the approach to the solution of outstanding problems in this field.

An opening address was given by Dr. P. Dunsheath, chairman of convocation of the University of London, in which he commented on the value of postgraduate schools in facilitating and extending the interchange of knowledge and ideas between specialists of long experience and the more junior members of industry and in reducing the time-lag in the use of new information. He then drew on his long experience of cable manufacture in an interesting historical review of early developments in insulating materials and of the difficulties which were encountered and overcome when little was known of the principles underlying their behaviour.

In the first lecture Prof. Willis Jackson, of the Imperial College of Science and Technology, London, discussed the problems facing the insulation engineer, surveyed the historical development of the widely used materials based on natural products and of the more recent synthetic materials, and outlined the progress which has been made towards explaining the electrical, physical and mechanical properties of these materials in terms of their chemical composition and physical structure. He was followed by Dr. L. Hartshorn, of the Electricity Division, National Physical Laboratory, Teddington, who spoke on the phenomena of permittivity and dielectric loss, with particular reference to the effects on them of temperature, humidity and oxidation.

The third lecture, by Dr. S. Whitehead, director of the Electrical Research Association, dealt in a comprehensive manner with existing knowledge of the mechanisms of intrinsic and thermal dielectric breakdown, and of breakdown due to external or internal discharges. Dr. Whitehead also discussed the effect on the electric strength of electrochemical deterioration in service, and the scope for improvement in materials, design and testing. Another member of the Electrical Research Association, Mr. C. G. Garton, then spoke on the structural basis of electrical and mechanical properties, and gave a very illuminating treatment of rate processes in relation to the dependence of these properties on temperature and frequency.

In the fifth lecture Mr. R. Snadow, of the British Thomson-Houston Co., Ltd., reviewed the available insulating materials in terms of the present thermal classification. He emphasized the inadequacy of this classification for some of the new synthetics, and that their application is being retarded by too limited knowledge of their thermal endurance.

The next five lectures were concerned with the applications of insulation in different classes of electrical equipment, and with the design problems involved. In discussing communication components, Mr. I. M. Ross, of the Ministry of Supply, referred to the extremely wide frequency-range with which the communication engineer has to deal, and the severe thermal and mechanical conditions to which military communication equipment, in particular, is subjected. After reviewing the changes in design which the use of new synthetic materials has made possible during recent years, he outlined the directions in which further improvement is required. Dr. L. G. Brazier, of British Insulated Callender's Cables, Ltd., dealt with the development of high-voltage cables and remarked that, in consequence of improvements which have occurred in the qualities of paper and oil and in the methods of cable fabrication, the oil-paper dielectric introduced by Ferranti some fifty years ago remains the only form of dielectric suitable for use at the highest operating voltages. He outlined the outstanding problems and the methods being adopted to resolve them. The design of power capacitors, and the manner in which this might be affected in the near future by the use of the new ceramics based on barium titanate, was then discussed by Dr. R. S. Vincent, of British Dielectrics Research, Ltd.

Mr. E. Jones, of the English Electric Co., Ltd., made a comprehensive review of the insulation problems involved in the design of electrical machines and indicated possible lines of approach to a more efficient use of insulation, and the reasons why, except to meet special requirements, there is no great need for, nor likelihood of, a marked increase in operating temperatures. The subject of transformers was dealt with by Mr. D. McDonald, of the British Thomson-Houston Co., Ltd. After discussing the electrical, mechanical and thermal requirements of transformer insulation design and the problems involved in satisfying them, he illustrated the trends of high-voltage transformer design by consideration of the shielded cylindrical layer-type winding. $\mathrm{He}_{\Theta}$ brought out the increasing similarities with cable construction and the movement towards the exclusive use at the highest voltages of the oil - paper dielectric. Mr. P. G. Ashley, of the Metropolitan- 
Vickers Electrical Co., Ltd., then discussed the insulation of switchgear. He surveyed the main uses of insulation, for supports, fillers and coverings, and the suitability of available materials for these purposes and, after emphasizing the need for fuller information concerning the long-term stability of materials and the difficulties of obtaining it, concluded by remarking that technically, if not economically, $500-\mathrm{kV}$. switchgear is a feasible proposition.

The final lecture, by Dr. J. S. Forrest, of the Research Laboratories of the British Electricity Authority, was concerned with the testing of insulation in the laboratory, factory and field. He classified the tests in use according to their function and advised on the interpretation of test results; he emphasized the need for constant review of the methods of test directed towards the formulation of a scheme of testing which would reflect the service conditions to be met as faithfully as possible $\mathrm{He}$ remarked that such an approach would assist in improving the present inadequate correlation between laboratory, factory and field tests.

The specialized discussions which followed the individual lectures were supplemented by a general discussion during the final session, when attention was devoted to questions such as the availability of new materials; the inadequacies of the present classification; the much more satisfactory understanding of the electrical mechanisms of dielectric behaviour compared with those governing the physical and mechanical properties, and finally, the desirability of increased and more fundamental attention to materials in courses leading to degrees and national certificates in electrical engineering. Visits were made during the course to the laboratories of the Electrical Research Association and the British Insulated Callender's Cables, Ltd.

\section{BRITISH SCIENTIFIC INSTRUMENT RESEARCH ASSOCIATION OPEN DAYS}

$\mathrm{W}$ ITH whatever feelings one regards the advancing front of science, it is obvious that the operation of new processes and new techniques, which give force to ideas and actions based on them, is maintained and nourished by the development of scientific instruments. These are tools of industry as well as of research. Thus the practice of the art and craft of instrument-making is a key industry, and it is significant that the British Scientific Instrument Research Association was the first of the industrial research associations, being founded in 1918. The laboratories of the Association are situated near Chislehurst in park-like surroundings, and when members and friends were entertained there on the recent open days (November 5 and 6 ) the weather was mild and clement enough to reinforce the pleasure of the occasion.

For thirty years the work of the Association was carried on in a house in Russell Square, London, and was mainly concerned with the manufacturers of optical instruments. This is not the place to report on the vicissitudes and difficulties of the early years, but in the outcome there has been very considerable development. During and since the Second World War the membership has greatly expanded, as has the scope of the experimental work undertaken, and the facilities provided at Chislehurst are comprehensive and impressive. No great powers of observation are required by the visitor to confirm that the Association is an integral part of the scientific instrument-making industry.

Research associations, though having essential similarities, differ markedly from one another in a variety of ways which reflect the character, scope and state of scientific development of the industries which they serve. Some of them are able to concentrate on the behaviour and manipulation of narrow groups of raw materials or types of processes on which their industries depend. In this sense the field may be relatively narrow, or at least the boundaries may be reasonably well defined. The British Scientific Instrument Research Association must have a broader outlook, for it serves an industry which itself serves a great variety of other industries, and to these must be added the Armed Services, universities and scientific establishments of all kinds. In general, of course, testing and instrumentation are subjects on which a considerable contribution is made to individual industries by their respective research organizations, but there remains an extensive region for activity by the Association.

The original and continuing emphasis on optical work was illustrated during the open days by demonstrations of lens grinding and, judging from the interest displayed by visitors, many people were impressed by the speed and accuracy with which this can be accomplished to precise specifications by precision engineering set-ups. The Association has a small glass-making shop (a palette of colour glasses for artificial eye-making was displayed) and has made considerable contributions to the techniques of chemical analysis of optical glasses, as well as to the examination of such glasses by interferometry, polarimetry and microscopy, including the effects of ageing and attack by humid atmospheres, etc.

The utilization of modern synthetic resins in optical cements has evidently been developed with much satisfaction, and there were striking demonstrations of the preparation of polarizing films from suitable synthetics by molecular orientation, and of metallic mirrors, anti-reflexion films, interference filters for visible light, heat filters, etc., dependent on high-vacuum evaporation techniques.

The development of infra-red transparent materials has made a striking advance through the utilization of the fact (known for some time) that mixed crystals of thallium bromide and iodide are transparent to radiations in the region $0 \cdot 5-40 \mu$. The process was demonstrated of growing single crystals in vertical cylindrical crucibles by a progressive freezing of the melt from bottom to top. The material, known as $K R S-5$, can be ground and polished and is chemically stable.

Graticule production may be described as one of the Association's 'specialities'. The methods adopted are mainly photographic in character and were well illustrated, together with the preparation of resolution test-slides for projection lenses.

Relatively recently, with the increasing use of electronic devices, the Association has built up a department well equipped to deal with a variety of electrical problems, exemplified by work on thermionic valves and valve amplifiers, electrometer valves, resistors of low temperature coefficient, magnetic amplifiers, the effects of dust on electrical contacts, etc. By contrast with the apparent complexities of 